Article

\title{
Superhydrophobic Self-Assembled Silane Monolayers on Hierarchical 6082 Aluminum Alloy for Anti-Corrosion Applications
}

\author{
Amani Khaskhoussi ${ }^{1, *(D)}$, Luigi Calabrese ${ }^{2, *(D)}$ and Edoardo Proverbio ${ }^{2}$ D \\ 1 National Interuniversity Consortium of Materials Science and Technology, INSTM, Via Giuseppe Giusti 9, \\ 50121 Firenze, Italy \\ 2 Department of Engineering, University of Messina, Contrada di Dio Sant'Agata, 98166 Messina, Italy; \\ eproverbio@unime.it \\ * Correspondence: khaskhoussiamani105@gmail.com (A.K.); lcalabrese@unime.it (L.C.)
}

Received: 10 March 2020; Accepted: 10 April 2020; Published: 12 April 2020

check for updates

\begin{abstract}
In this work, a two-stage methodology to design super-hydrophobic surfaces was proposed. The first step consists of creating a rough nano/micro-structure and the second step consists of reducing the surface energy using octadecyltrimethoxysilane. The surface roughening was realized by three different short-term pretreatments: (i) Boiling water, (ii) $\mathrm{HNO}_{3} / \mathrm{HCl}$ etching, or (iii) $\mathrm{HF} / \mathrm{HCl}$ etching. Then, the surface energy was reduced by dip-coating in diluted solution of octadecyltrimethoxysilane to allow the formation of self-assembled silane monolayers on a 6082-T6 aluminum alloy surface. Super-hydrophobic aluminum surfaces were investigated by SEM-EDS, FTIR, profilometry, and contact and sliding angles measurements. The resulting surface morphologies by the three approaches were structured by a dual hierarchical nano/micro-roughness. The surface wettability varied with the applied roughening pretreatment. In particular, an extremely high water contact angle (around $\left.180^{\circ}\right)$ and low sliding angle $\left(0^{\circ}\right)$ were evidenced for the $\mathrm{HF} / \mathrm{HCl}$-etched silanized surface. The results of electrochemical tests demonstrate a remarkable enhancement of the aluminum alloy corrosion resistance through the proposed superhydrophobic surface modifications. Thus, the obtained results evidenced that the anti-wetting behavior of the aluminum surface can be optimized by coupling an appropriate roughening pretreatment with a self-assembled silane monolayer deposition (to reduce surface energy) for anticorrosion application.
\end{abstract}

Keywords: superhydrophobicity; self-assembly; anticorrosion; aluminum

\section{Introduction}

Super-hydrophobicity is one of the highly required surface properties for several industrial applications for which specific surface properties are required (such as anti-corrosion, anti-icing, self-cleaning, or anti-bioadhesion applications) [1]. In this context, numerous methods have recently been suggested to design super-hydrophobic hierarchical surfaces inspired by nature [2,3]. The superhydrophobic surfaces represent an interesting approach to maximizing the resistance to corrosion of materials usually sensitive to corrosion degradation, particularly aluminum and its alloys, by the dint in their capacity to reduce the interaction between metallic surfaces and liquids [4-6].

However, the proposed approaches usually require complex synthesis processes and production technologies that are not easily scalable. Moreover, several methods used to elaborate superhydrophobic surfaces require chemicals that are unsafe to the environment and human health such as fluorinated compounds.

Therefore, the optimization of a facile, inexpensive, and environmentally friendly experimental approach to create superhydrophobic surfaces is greatly desired. According to Ruan et al. [7], who 
studied different surface hydrophobizing techniques, the selection of experimental parameters have a great effect on the surface properties and, thus, on the superhydrophobic behavior of the samples. In particular, Chen et al. [8] observed that the chemical etching time has an important effect on the change in the wettability behavior of the aluminum surface from hydrophilic to hydrophobic. Shi et al. [9] produced a superhydrophobic surface on an aluminum sample using a two-step process. First, the aluminum was hydrothermally treated to create a flower-like hierarchical structure. Afterward, the obtained surface was treated by lauric acid to reduce the surface free energy.

In particular, some studies focused on the corrosion inhibition of superhydrophobic surfaces. Indeed, Dou et al. [10] showed in their study of the corrosion behavior of a copper superhydrophobic surfaces that the resistance to corrosion of these surfaces increased by more than $10^{2}$ times in a marine environment.

Moreover, the superhydrophobic surfaces optimized by Li et al. [11] on $6061 \mathrm{Al}$ alloy showed a corrosion resistance efficiency of about $76 \%$ compared to the hydrophobic surface. In addition, Feng et al. [12] created a superhydrophobic surface with a water contact angle above 156 and a sliding angle of about $3^{\circ}$ on an $\mathrm{Al}$ alloy characterized by a long-term corrosion resistance.

On the other hand, several studies showed that the deposition of a self-assembled silane monolayer on the surface is an efficient strategy to reduce the surface energy and improve the surface hydrophobicity [11,13-17]. The self-assembly is a convenient route to prepare well-defined and highly ordered monolayers $[18,19]$. In contrast to ultrathin films made by chemical vapor deposition (CVD), and molecule beam epitaxy (MBE), self-assembled monolayers are highly oriented and can incorporate a wide range of groups both at the chain terminal and in the alkyl chain [20]. Moreover, thanks to their stable and dense structure, self-assembled monolayers have possible applications in wear protection, corrosion prevention, chemical and biochemical sensing, and the optical field. Among several self-assembled films, alkylsilane exhibits favorable properties such as mechanical and chemical stability thanks to the strong siloxane bondings [21,22].

However, even if significant efforts have been carried out to elaborate superhydrophobic surfaces, the multi-step preparation and relatively high costs are still drawbacks for their wide use in industrial applications. Thus, further knowledge on manufacturing methods is required for the purpose of better understanding the relationship between the hierarchical structure and the wettability behavior of the surfaces to enhance the corrosion inhibition.

In the present study, different superhydrophobic surfaces were prepared through the combination of three types of roughening approaches and low-surface-energy self-assembled alkylsilane on a 6082-T6 Al alloy. Micro/nano-roughness morphologies were obtained by three pre-treatments: (1) Boiling treatment, (2) etching using $\mathrm{HNO}_{3} / \mathrm{HCl}$ solution, and (3) chemical etching in $\mathrm{HCl} / \mathrm{HF}$ solution. Subsequently, a self-assembled silane monolayer was applied on the rough surfaces via the dip-coating process to exalt the hydrophobicity of these surfaces. Different superhydrophobic surfaces were effectively prepared using these methods. Several techniques were used to characterize these surfaces and deeply understand the effect of the morphology on their performances.

\section{Materials and Methods}

First, 6082-T6 aluminum alloy specimens (size: $3 \mathrm{~cm} \times 2.4 \mathrm{~cm} \times 0.2 \mathrm{~cm}$ ) obtained from a $100 \times 100 \times 0.2 \mathrm{~cm}^{3}$ commercially laminated plate (chemical composition: Si $0.70-1.3 \%$; Mg $0.60-1.2 \%$; $\mathrm{Fe} \leq 0.50 \% ; \mathrm{Cu} \leq 0.10 \% ; \mathrm{Mn} 0.40-1.0 \% ; \mathrm{Cr} \leq 0.25 \% ; \mathrm{Zn} \leq 0.20 \% ; \mathrm{Ti} \leq 0.10 \%$ and balance $\mathrm{Al}$ ) were used as substrates. Octadecyltrimethoxysilane $\left(\mathrm{C}_{21} \mathrm{H}_{46} \mathrm{O}_{3} \mathrm{Si}, 90 \%\right)$ and hydrofluoric acid (48\% concentration) were purchased from Sigma-Aldrich. Hydrochloric acid (37\% concentration) and nitric acid (60\% concentration) were purchased from Carlo Erba. In addition, bi-distilled water with a resistivity of 18.0 M $\Omega \cdot \mathrm{cm}$, from Best-Chemical, Vairono Patenora, Italy, was used throughout the experiments.

The as-received 6082 aluminum alloy samples were ultrasonically cleaned in ethanol, acetone, and ultra-pure water for $5 \mathrm{~min}$ before roughening treatment. In order to create a hierarchical structure on the aluminum surface, the samples were divided into three batches: The first batch was treated 
in boiling water for $5 \mathrm{~min}$, the second one was chemically etched in $\mathrm{HNO}_{3} / \mathrm{HCl}$ (1:3) for $1 \mathrm{~h}$, and the third one was etched in Beck's $\mathrm{HF} / \mathrm{HCl}$ solution for $15 \mathrm{~s}$. Then, the made specimens were ultrasonically washed and dried at $70{ }^{\circ} \mathrm{C}$ for $1 \mathrm{~h}$. Afterward, the rough samples were immersed in $1 \mathrm{vol} . \%$ octadecyltrimethoxysilane/toluene solution for $10 \mathrm{~min}$ at room temperature and dried in an oven at $100{ }^{\circ} \mathrm{C}$ for $180 \mathrm{~min}$ for silane curing. All the parameters were optimized based on the literature [23-25] and preliminary tests performed in our laboratory. Table 1 illustrates the specimen details.

Table 1. Samples details.

\begin{tabular}{ccc}
\hline Code & Step 1 & Step 2 \\
\hline A_R & - & - \\
A_RS & - & Silane \\
A_W & Boiling water & - \\
A_WS & Boiling water & Silane \\
A_N & $\mathrm{HNO}_{3} / \mathrm{HCl}$ & - \\
A_NS & $\mathrm{HNO}_{3} / \mathrm{HCl}$ & Silane \\
A_F & $\mathrm{HF} / \mathrm{HCl}$ & - \\
A_FS & $\mathrm{HF} / \mathrm{HCl}$ & Silane \\
\hline
\end{tabular}

The surface morphologies of the specimens were studied by using a focused ion dual beam/scanning electron microscope (FIB-SEM ZEISS Crossbeam 540). Moreover, the coating composition was evaluated via energy-dispersive spectroscopy (Aztec Oxford, EDS). The roughness of the surfaces was measured using the profilometer SJ-210 (Mitutoyo, Japan).

The static water contact angles (WCAs) of the different aluminum surfaces were measured using an Attension Theta Tensiometer (Biolin Scientific, Sweden) following the sessile drop technique $(\approx 3 \mu \mathrm{L})$. The sliding angles (WSA) were recorded by tilting the platform until the water droplets rolled off the surfaces. For each treatment step, five samples were prepared in order to ensure the reproducibility of the process. Fifty replicas of water contact angle (WCA), located on the surface to obtain a regular grid, for each sample were performed, and the average values and standard errors of WSA and WCA were calculated.

Electrochemical measurements were performed, using a BioLogicSP-300 potentiostat, at ambient temperature in simulated seawater $(3.5 \mathrm{wt} . \% \mathrm{NaCl}$ solution) open to air. A standard three-electrode cell, having a platinum wire as the counter electrode, a saturated $\mathrm{Ag} / \mathrm{AgCl}$ electrode as the reference electrode, and the superhydrophobic sample as the working electrode, was used as the working cell. The exposed area of the working electrode was $1 \mathrm{~cm}^{2}$. Prior to the test, each sample was in contact with the $\mathrm{NaCl}$ solution for $30 \mathrm{~min}$ to ensure the steady state. The potentiodynamic polarization curves were collected with a scanning rate of $0.2 \mathrm{mV} / \mathrm{s}$.

\section{Results and Discussions}

\subsection{Surface Morphology and Roughness}

The effect of the manufacturing process on the sample surface was primarily evaluated by morphological studies.

Figure 1 shows SEM images of the aluminum alloy samples prepared by the three roughening processes: Boiling (A_WS), $\mathrm{HF} / \mathrm{HCl}$ etching (A_FS), and $\mathrm{HNO}_{3} / \mathrm{HCl}$ etching (A_NS). Clear modifications were observed on all the surfaces after the roughening treatment. However, the silane self-assembled monolayer did not affect the surface morphologies. Combined micro/nano-structures were formed after the boiling treatment and the two types of acidic etching. The different surfaces are characterized by high homogeneity thanks to the efficient and no localized pretreatment. However, different sorts of surface morphologies can be identified. 
a)

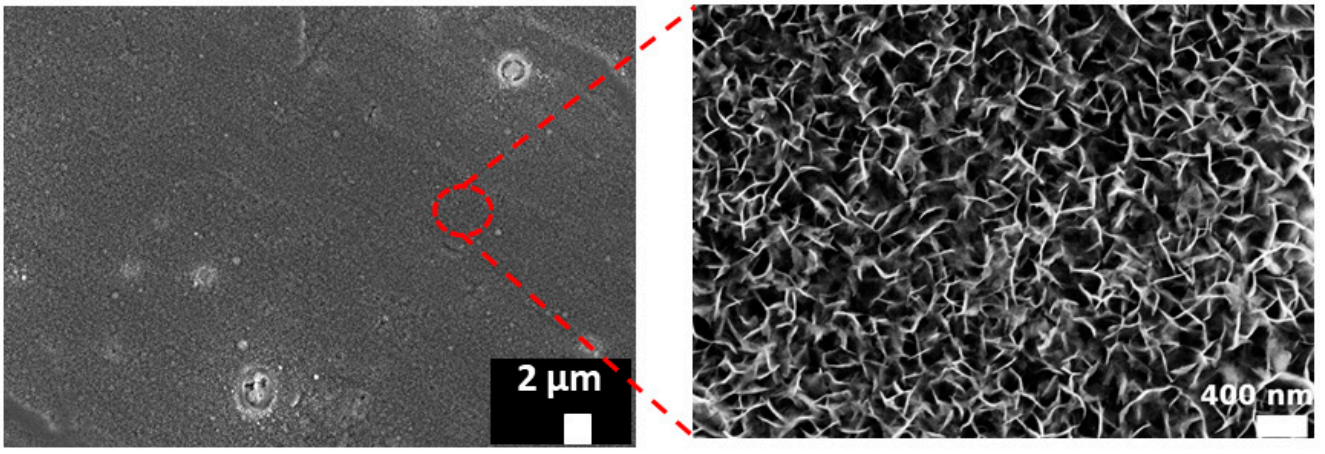

b)

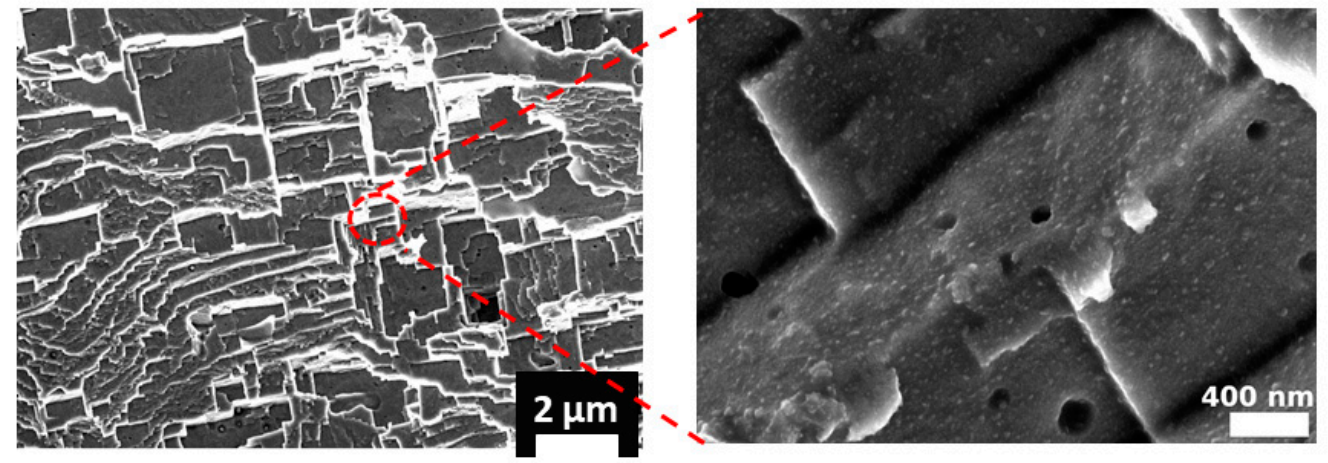

c)

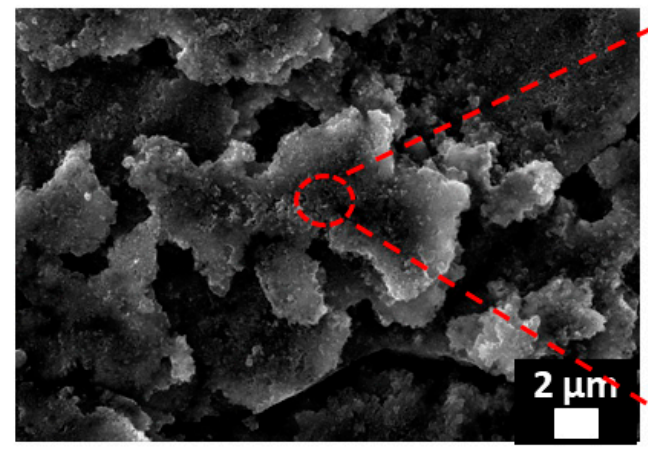

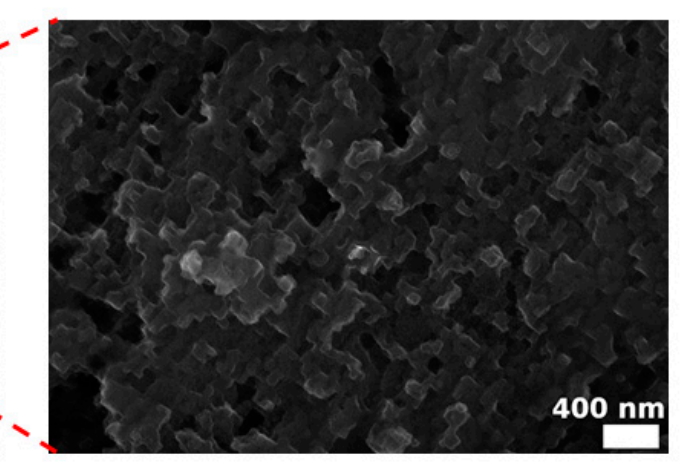

Figure 1. Low-magnification and high-magnification SEM images of aluminum alloy sample prepared by (a) boiling (A_WS), (b) $\mathrm{HNO}_{3} / \mathrm{HCl}$ etching (A_NS), and (c) $\mathrm{HF} / \mathrm{HCl}$ etching (A_FS).

Several flower-like petals with thicknesses of about $20-30 \mathrm{~nm}$ and a great deal of cavities with diameters around $100 \mathrm{~nm}$ appear at the boiled aluminum surface. The adjacent flower-like petals overlap and connect with each other, creating, during its growth, a micro/nano-structure. In fact, in the initial stage of the aluminum substrate immersion in boiling water, a reaction between the $\mathrm{Al}$ and $\mathrm{H}_{2} \mathrm{O}$ occurs:

$$
2 \mathrm{Al}+(3+\chi) \mathrm{H}_{2} \mathrm{O} \rightarrow \mathrm{Al}_{2} \mathrm{O}_{3} \cdot \chi \mathrm{H}_{2} \mathrm{O}+3 \mathrm{H}_{2} \uparrow
$$

Thus, $\mathrm{Al}$ at the surface of the $\mathrm{AA} 6082$ transforms into $\mathrm{Al}_{2} \mathrm{O}_{3} \cdot \chi \mathrm{H}_{2} \mathrm{O}$. This latter reacts with $\mathrm{H}_{2} \mathrm{O}$ to generate an $\mathrm{AlO}(\mathrm{OH})$ crystal called boehmite, resulting in the flower-like rough structure $[6,12,26,27]$.

Moreover, the surface etched with $\mathrm{HNO}_{3} / \mathrm{HCl}$ solution appears as a multiple-scale structure with dimensions of 2 to $4 \mu \mathrm{m}$ (microstructure). Nanometric pits, with dimensions lower than $200 \mathrm{~nm}$, are randomly nucleated on the aluminum surface of these scales [25]. This bimodal structure is formed thanks to the associated action of the two acids [28]. The vigorous reaction of the aluminum alloys with the hydrochloric acid probably induced the formation of the microscales following the crystallographic orientation. However, the nitric acid, which is an oxidizing acid that can have a passivation property, has low corrosive action on the aluminum alloy. Thus, it can participate only on the formation of nano-pits [29]. 
On the other hand, the structure formed by the $\mathrm{HF} / \mathrm{HCl}$ etching is totally different from the $\mathrm{HNO}_{3} / \mathrm{HCl}$ one. In fact, this etching induced the formation of large deep attack zones in the microscales and a large amount of clean-cut and rugged nano-ladder structures over the AA6082-T6 surface.

The main reason for the deep attack zone's appearance is the presence of the several dislocation defects and the crystal boundaries in the aluminum alloy with a relatively greater energy in crystalline metals that are prone to damage when attacked by etchants [30,31]. In particular, HF has a great effect in dissolving the silicon (Si) impurities distributed on the aluminum alloy surface [32].

In order to quantify the different surface morphologies in the surface structure, the roughness parameters: $\mathrm{Ra}, \mathrm{Rq}$, and $\mathrm{Sku}$, were determined using a Mitutoyo profilometer. Ra is the arithmetic average of the absolute values of the profile heights, $\mathrm{Rq}$ is the root-mean-square average of the profile roughness, and Sku is a measure of the height distribution and provides information about the number of valleys and hills on the surface [33]. As the basic strategy behind creating a superhydrophobic surface is making a hierarchical structure, the roughness parameters $\mathrm{Ra}$ and $\mathrm{Rq}$ are not enough to explain the superhydrophobicity; we need other factors such as the skewness parameter to complete interpretation. In fact, the Sku parameter measurement showed that the method of roughening has a great effect on the peaks/valleys distribution [34]. These parameters are summarized in Table 2. The as-received (A_R) sample has a low roughness of $\mathrm{Ra}=0.254 \mu \mathrm{m}$ and $\mathrm{Rq}=0.301 \mu \mathrm{m}$. Moreover, $\mathrm{Sku}(=0.256)$ indicates that the height distribution on the A_R surface is symmetric. After treatment with the different roughening processes, the surface roughness clearly increased. In fact, the A_WS sample is characterized by a positive skewness value (1.063), indicating a large number of peaks and a few valleys on the surface. Thus, the silane layer is likely mainly deposited on the peaks of this surface. However, the negative skewness obtained on the A_NS surface indicates a greater percentage of the profile above the mean line and a number of valleys higher than the number of peaks. On the other hand, the Sku value of the A_FS sample is around zero (0.234), indicating a symmetric and regular distribution of peaks and valleys on the surface [35]. These different profiles are illustrated in Figure 2.

Table 2. Roughness parameters of different prepared samples.

\begin{tabular}{cccc}
\hline Samples & $\begin{array}{c}\text { Arithmetic Roughness Ra } \\
(\mu \mathrm{m})\end{array}$ & $\begin{array}{c}\text { Root-Mean-Square Roughness Rq } \\
(\boldsymbol{\mu m})\end{array}$ & Skewness (Sku) \\
\hline A_R & 0.254 & 0.301 & 0.256 \\
A_WS & 0.297 & 0.382 & 1.063 \\
A_NS & 4.151 & 4.800 & -0.783 \\
A_FS & 1.427 & 1.722 & 0.243 \\
\hline
\end{tabular}
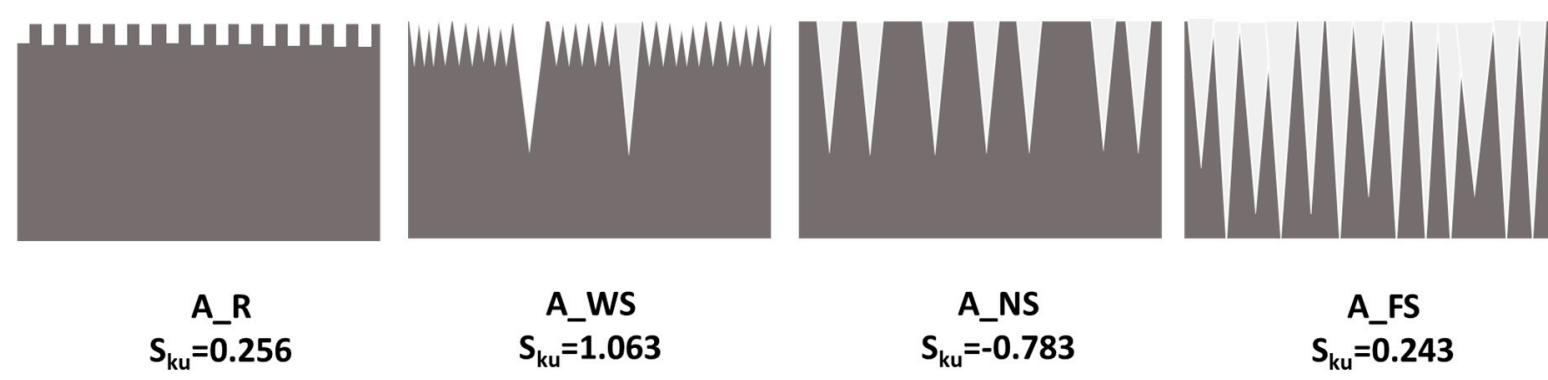

Figure 2. Scheme of the as-received (A_R), A_WS, A_NS, and A_FS profiles.

\subsection{Element Analysis}

The EDS technique was used to investigate the chemical compositions of surfaces.

Figure 3 shows the recorded EDS spectra of the as-received surface A_R (a) and the treated surfaces A_WS (b), A_NS (c), and A_FS (d). The EDS quantitative analysis of the A_R aluminum substrate reveals a composition rich in $\mathrm{Al}$ and confirms the presence of the alloy elements $\mathrm{Si}, \mathrm{Mg}, \mathrm{Mn}$, and Fe. Small peaks of carbon and oxygen were also evidenced, due to contamination. However, the 
spectra of the treated surfaces reveal a great increase in the percentages of $\mathrm{C}$ and $\mathrm{O}$, indicating that a silane layer was successfully grafted on the rough aluminum substrate [26,36].
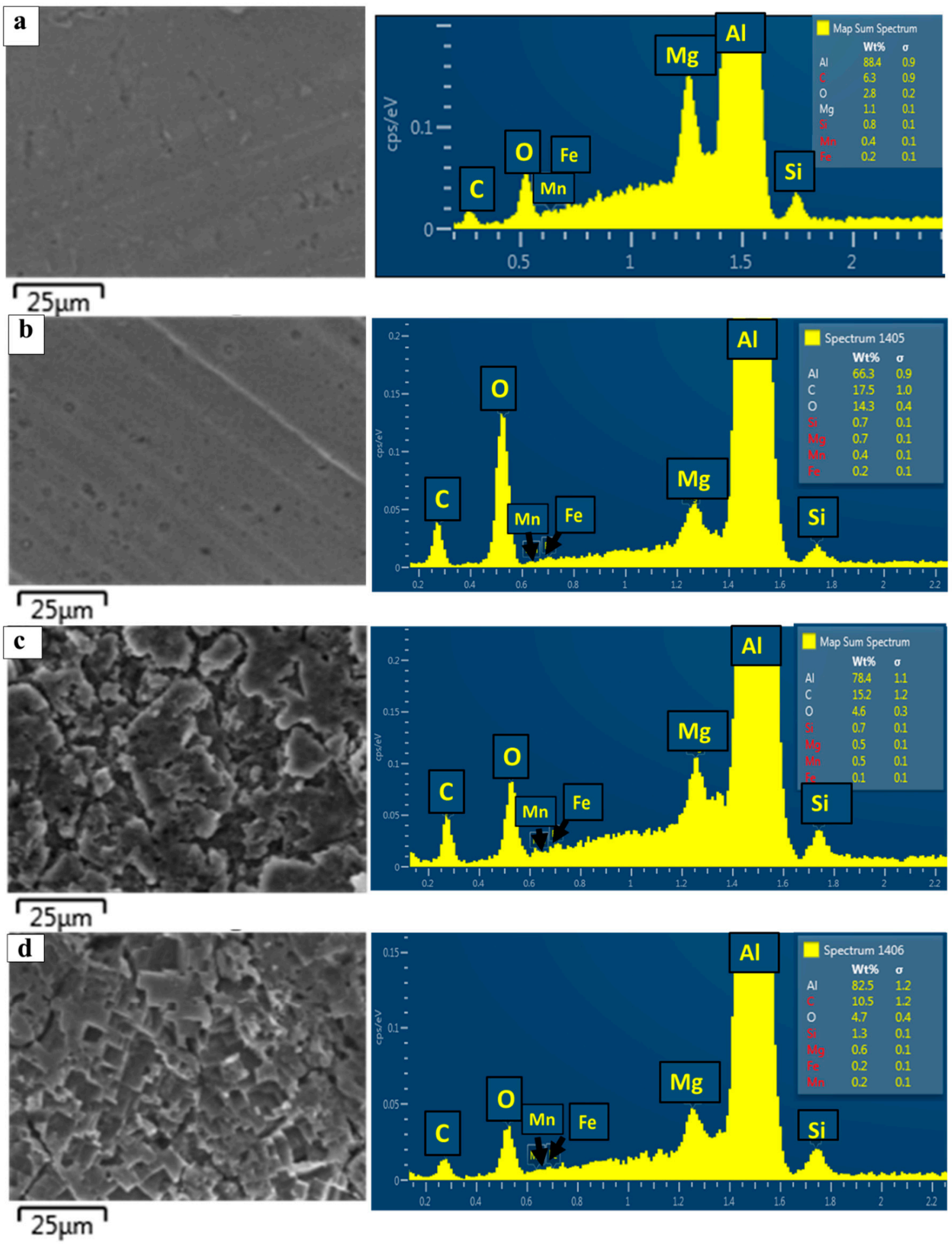

Figure 3. EDS spectra of A_R (a), A_WS sample (b), A_NS sample (c), and A_FS sample (d).

Figure 4 shows FTIR spectra of A-WS. In this spectrum, the broad peak at $3450 \mathrm{~cm}^{-1}$ is assigned to the stretching vibration of silanol (O-H group). The peaks at 950 and $800 \mathrm{~cm}^{-1}$ are due to Si-O stretching and the deformation of Si-OH, respectively, in silanol. The peaks at 1100 and $470 \mathrm{~cm}^{-1}$ are due to asymmetric and symmetric stretching of $\mathrm{Si}-\mathrm{O}-\mathrm{Si}$ in the siloxane group, respectively. This spectrum 
also reveals the presence of two peaks of around 2930 and $2840 \mathrm{~cm}^{-1}$, which are characteristic bands of silane corresponding to symmetric and antisymmetric stretching of the $-\mathrm{CH}_{2}$ group, respectively. The presence of these bands could be attributed to the entanglements of hydrocarbon chains after the monomer due to the polymerization on a surface and also to the effect of neighboring electrons drawing a carbonyl group [37]. The small peak at $1450 \mathrm{~cm}^{-1}$ corresponds to the $\mathrm{Si}-\mathrm{CH}_{2}$ bending vibration present in silane [38]. Thus, the presence of these characteristic bands of silane in the spectrum of A-WS confirms the formation of a self-assembled silane monolayer on the surface of the aluminum substrate.

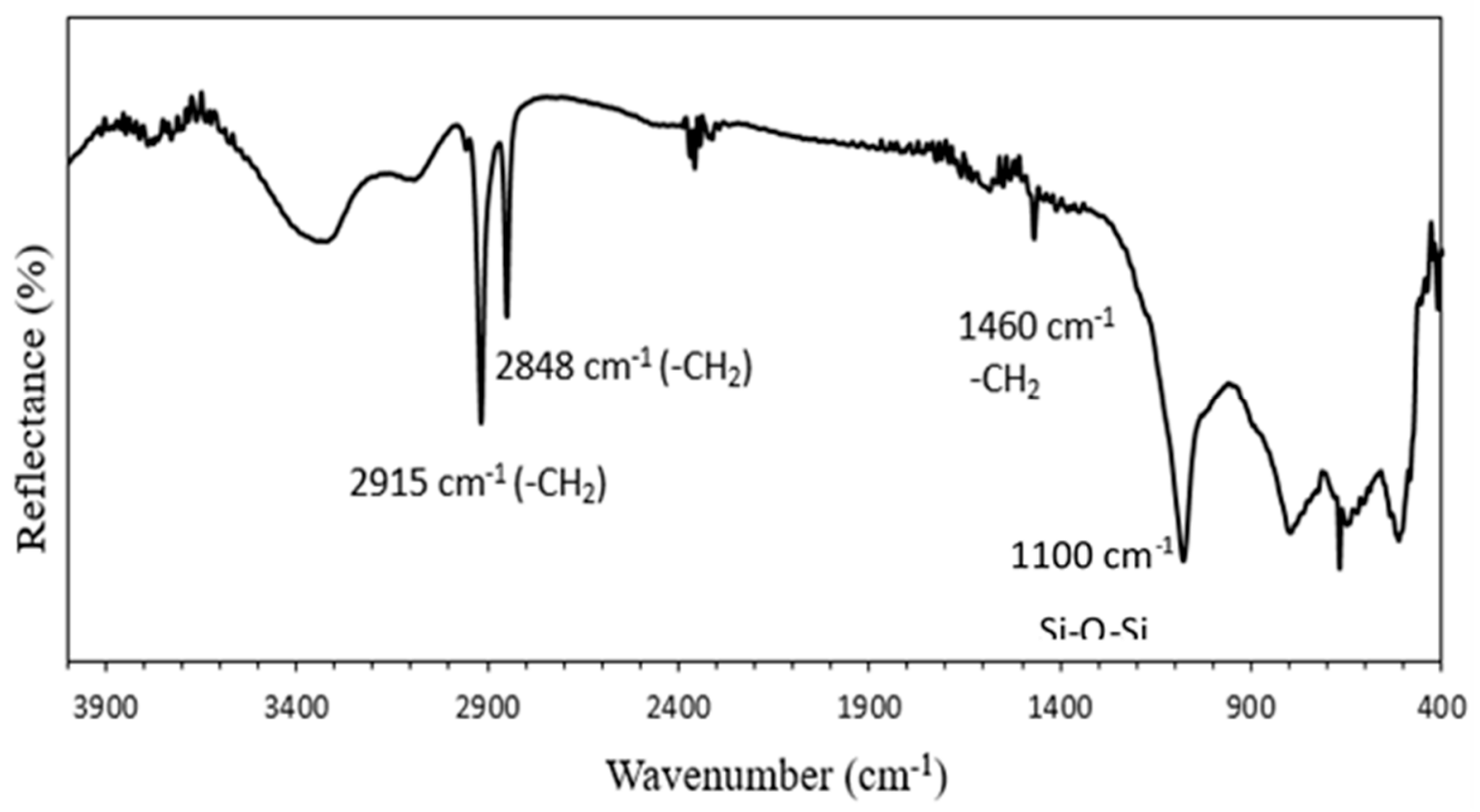

Figure 4. FTIR spectra of A-WS surface.

\subsection{Wettability Behavior}

In order to assess the relationship between the different obtained morphologies and the surface wettability behavior, the water contact angles of the as-received and modified samples were measured and are shown in Figure 5 and Table 3.

Table 3. Summary of water contact and sliding angles at AA6082 surfaces after different treatment steps.

\begin{tabular}{ccc}
\hline Samples & CA $\left(^{\circ}\right)$ & SA $\left(^{\circ}\right)$ \\
\hline A_R & $69 \pm 3^{\circ}$ & - \\
A_RS & $101 \pm 2^{\circ}$ & $55 \pm 6^{\circ}$ \\
A_W & $16 \pm 2^{\circ}$ & - \\
A_WS & $174 \pm 3^{\circ}$ & $>90^{\circ}$ \\
A_N & $23 \pm 3^{\circ}$ & - \\
A_NS & $160 \pm 3^{\circ}$ & $26 \pm 5^{\circ}$ \\
A_F & $12 \pm 2^{\circ}$ & - \\
A_FS & $179 \pm 3^{\circ}$ & $0^{\circ}$ \\
\hline
\end{tabular}

After roughening pretreatment, the aluminum alloys, ultrasonically cleaned and dried, showed static contact angles lower than $25^{\circ}$ with water in accordance with Wenzel theory. Indeed, as stated by the theory of Wenzel, the wettability of the hydrophilic surface increases when its roughness increases. The substrates after the growth of the self-assembled silane monolayer exhibited a great change in the surface states by altering their wetting properties. 


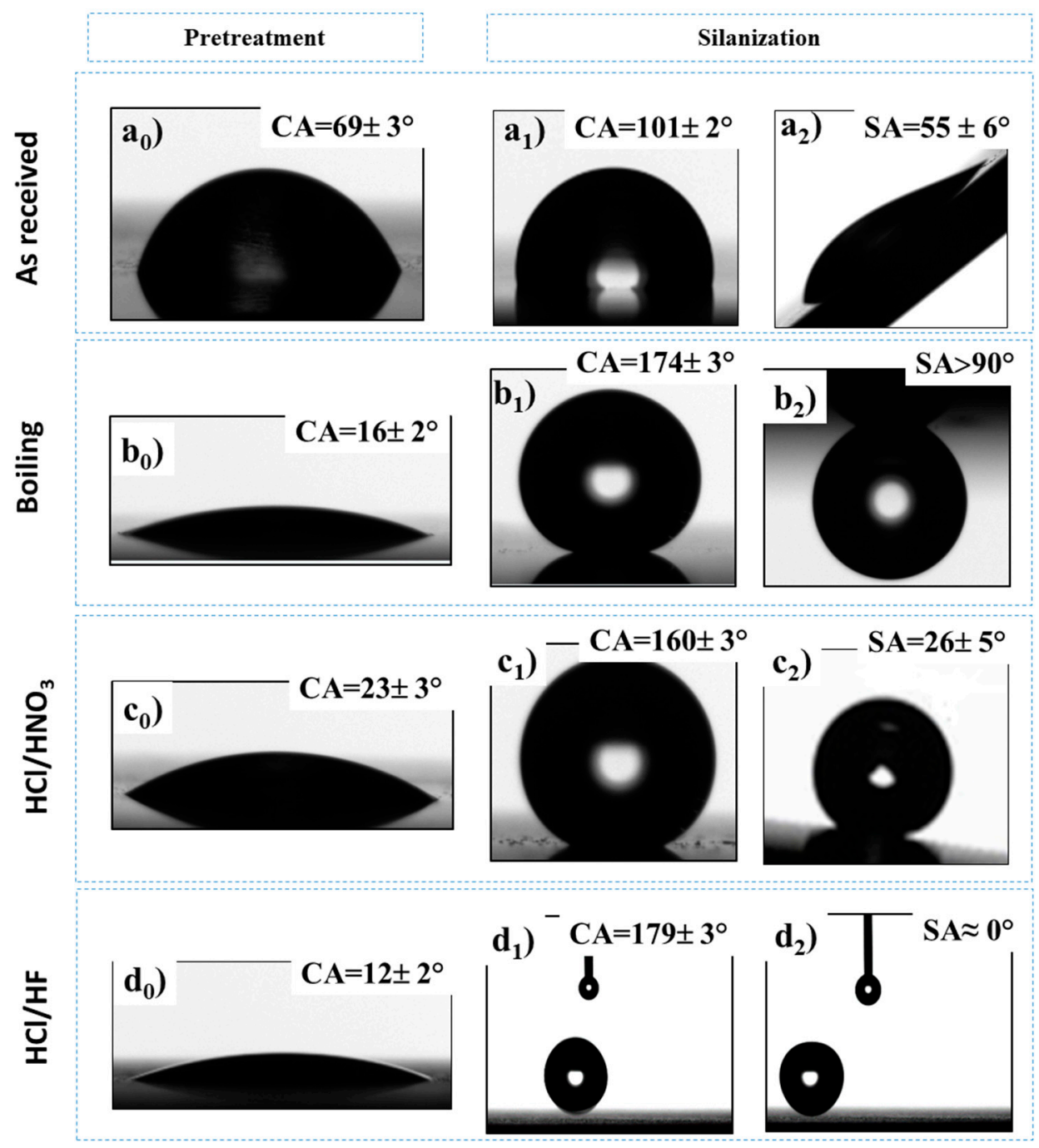

Figure 5. Images of water contact angles (CAs) and sliding angles (SAs) with average values and errors on $\mathrm{Al}$ alloys surface: $\left(\mathbf{a}_{\mathrm{i}}\right)$ A_R; $\left(\mathbf{b}_{\mathrm{i}}\right)$ A_W; $\left(\mathbf{c}_{\mathrm{i}}\right)$ A_N; $\left(\mathbf{d}_{\mathrm{i}}\right)$ A_F where $\mathrm{a}_{0}$ is the just-cleaned sample, $\mathrm{b}_{0}$ is the boiled sample, and $c_{0}$ and $d_{0}$ are the etched samples.

The wettability of the surfaces depends sensitively on both surface morphology and surface energy. In fact, the roughening pretreatment induced the decrease in the water contact angle of the as-received aluminum surface from $69 \pm 3^{\circ}$ to $<25^{\circ}$. Then, these surfaces became superhydrophobic with a water contact angle higher than $150^{\circ}$ after silane deposition. This rise in contact angle is a result of the reduction in the surface energy thanks to the alignment of hydrophobic organic alkyd chains on the topside of the self-assembled silane monolayer. We also evaluated the effect of silane deposition on the surface of the as-received surface. The water contact angle of the A_R surface increased from around $69^{\circ}$ to around $101^{\circ}$ after silanization, confirming the decrease in the surface energy. The best result was observed for the A_FS sample that is characterized by an average water CA of around $180^{\circ}$ and a very low water sliding angle $\left(\approx 0^{\circ}\right)$. In fact, the water droplet fell down, hit the substance, and directly rebounded upward before rolling off the $\mathrm{Al}$ surface without any residual water. Instead, the A_NS sample showed an average WCA of about $160^{\circ}$ with an intermediate WSA $\left(26 \pm 5^{\circ}\right)$, and the A_WS was characterized by an WCA of about $174^{\circ}$ and a high water adhesion on its surface $\left(\mathrm{SA}>90^{\circ}\right)$. This difference on the water repellency behavior between the three batches is due to the transition between Wenzel and Cassie-Baxter regimes [24]. According to Wenzel's model, the water fully penetrates the surface valleys [39]. Thus, it is a homogeneous wetting mode resulting in a high contact angle and high water adhesion to the surface. However, in the Cassie-Baxter model, the surface 
roughness traps air pockets and the water rests on the air/solid interface; thus, the water droplets on the surface are easy to roll [40].

The air entrapped in the liquid/solid interface of the A_FS surface reduces the contact area between the water droplet and the sample surface, according to the Cassie-Baxter state, inducing a high water repellency at a null sliding angle. However, for the A_WS, the liquid fully penetrates in the surface cavities, forming a continuous water/substrate contact line resulting in a very high sliding angle $\left(>90^{\circ}\right)$ following the Wenzel state. On the other hand, $A \_N S$, with a sliding angle of about $S A \approx 25^{\circ}$, evidenced an intermediate state between Wenzel and Cassie-Baxter. Therefore, the adhesion behavior depends on the quantity of air entrapped on the substrate and, thus, on the morphology of the surface.

The self-assembled layers were grown by using toluene solution as an apolar reaction medium. Several solvents have been utilized in the literature, such as ethanol [41], toluene [25], and hexane [31], for self-assembled silane monolayers. However, only the polar solvents have been extensively used under the consideration that they dissolve the molecules well. Recently, Nie [42] demonstrated experimentally that the dielectric constant of the solvent has a great role in producing the self-assembled monolayers because it measures the ability of dissolving or separating charged particles. Thus, not only the polar solvent but also the apolar solvent with an appropriate dielectric constant is able to align and concentrate the polar head-groups of the molecules on its surface. Then, when physical contact between the hydrophilic substrate and the apolar medium occurs, the aligned silane molecules spontaneously transfer onto the hydrophilic surface, forming a self-assembled monolayer that makes the dip-coating suitable for industrial application [31,41,43]. In our case, the interaction between the octadecyltrimethoxysilane and the toluene probably renders a situation where the S18 molecules are well dispersed and oriented. These molecules spontaneously transfer and align on the aluminum alloy hydrophilic surface, forming a monolayer with oriented hydrophobic organic alkyl chains on the topside of this layer, as shown in Figure 6. The formation of the silane layer induced the reduction in surface energy and, thus, the reduction in the affinity of the surface with the polar liquids [44].

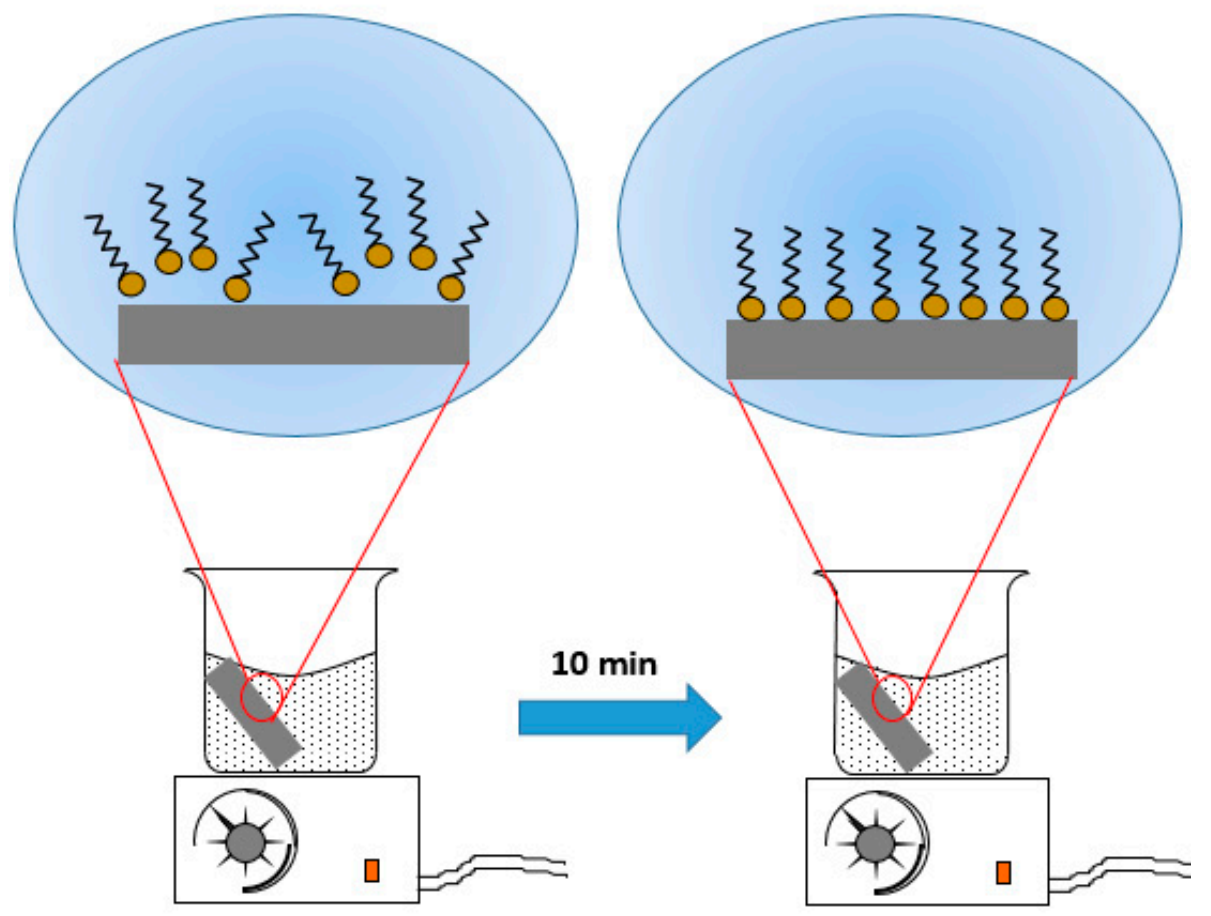

Figure 6. Illustration of octadecyltrimethoxysilane (S18) molecules, with wavy lines representing the hydrocarbon chain and yellow circles representing the head groups dissolved in toluene.

However, the difference in contact angles between the three superhydrophobic surfaces suggest that the polarity of the solvent is not the only factor that influences the orientation of the amphiphilic 
molecules but also the morphology of the surface. The silane functional long alkyl chains formed a monolayer on the aluminum surface thanks to the high reactivity of the $\mathrm{Si}-\mathrm{OH}$ silanol groups with the $\mathrm{Al}-\mathrm{OH}$ aluminum hydroxyl groups [45]. However, the silane monolayer structure, which strongly depends on the surface profile, cannot be optimized when the silanol groups interact only with limited surface sites.

On the surface of A_W, the flower-like structure overlapped and connected petals that may limit the silane deposition on the cavities. Indeed, the reaction between the silanol groups $(\mathrm{Si}-\mathrm{OH})$ of the silane and the hydroxyl groups (Al-OH) of the aluminum surface is limited on these narrow cavities that may induce a partial saturation of the $-\mathrm{OH}$ sites, resulting in a high water adhesion. However, the silane is mainly deposited in the A_N surface cavities due to the large number of valleys in this structure, as shown by the skewness factor, inducing the reduction in the surface roughness. This limits the contribution of the surface hierarchical structure on the superhydrophobic behavior where an intermediate water adhesion $\left(\approx 26^{\circ}\right)$ and quite low contact angle $\left(164^{\circ}\right)$, compared to the other surfaces, were observed. The synergic effect of the micro/nano-structure and the symmetric and regular distribution of the peaks and valleys on the A_F surface $(\mathrm{Sku} \approx 0)$ induced the formation of a uniform silane monolayer, resulting in a very high contact angle $\left(180^{\circ}\right)$ and great water repellency $\left(\mathrm{SA} \approx 0^{\circ}\right)$.

\subsection{Corrosion Resistance}

Superhydrophobic surfaces were elaborated by the three proposed methods. This reduction in the wettability of these surfaces may deeply affect their corrosion resistance. For this reason, the corrosion resistance of the prepared samples was evaluated.

Table 4 shows the open circuit potential values (OCPs), in seawater, of the different prepared samples. The results clearly demonstrate that the OCP is strongly influenced by the presence of silane on the aluminum alloy surface [46]. Indeed, all the silanized surfaces showed OCPs more noble than the non-silanized ones.

Table 4. Open circuit potential values (OCP) of AA6082 surfaces after different treatments steps in 3.5 wt. $\% \mathrm{NaCl}$ solution.

\begin{tabular}{cccc}
\hline Code & OCP(V) & Ecorr $(V$ vs. SCE) & Icorr $\left(\mu \mathbf{A} / \mathbf{c m}^{2}\right)$ \\
\hline A_R & -0.931 & -0.906 & 21.17 \\
A_RS & -0.786 & & \\
A_W & -0.769 & -0.735 & 0.04 \\
A_WS & -0.698 & -0.449 & 0.03 \\
A_N & -0.645 & & \\
A_NS & -0.537 & -0.419 & 0.03 \\
A_F & -0.620 & & \\
A_FS & -0.472 & & \\
\hline
\end{tabular}

In addition, the corrosion resistance can be roughly estimated by means of a potentiodynamic polarization test. Figure 7 shows the potentiodynamic curves recorded for the as-received sample (A_R) and the three superhydrophobic samples with different water contact angles/water sliding angles in $3.5 \mathrm{wt} . \% \mathrm{NaCl}$ solution. The electrochemical parameters such as the corrosion current density (Icorr) and the corrosion potential (Ecorr) derived from the potentiodynamic polarization using the Tafel extrapolation approach are also reported in this figure. A lower corrosion current density (Icorr) and a higher corrosion potential (Ecorr) indicate a better corrosion resistance [24,47]. 


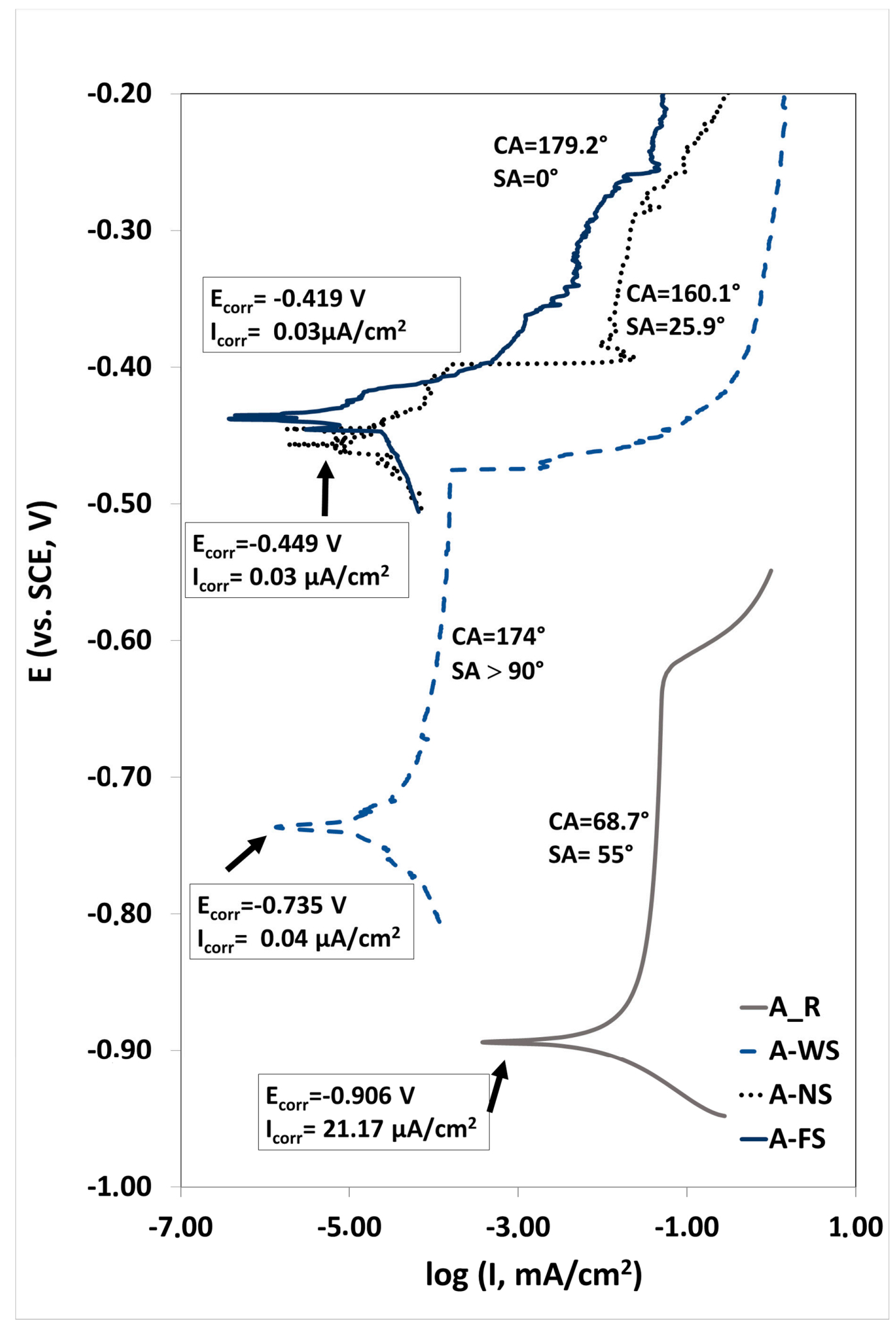

Figure 7. Polarization curves of A_R, A_WS, A_NS, and A_FS.

It can be seen that the corrosion potential of the aluminum alloy positively increases in the presence of superhydrophobic surfaces from -0.906 to $-0.734 \mathrm{~V}$ for the A_WS sample, -0.449 for the A_NS sample, and then $-0.419 \mathrm{mV}$ for the A_FS sample. The low corrosion resistance of the untreated 
aluminum alloy is due to the pitting corrosion that occurs after immersing in an aggressive environment containing $\mathrm{Cl}^{-}$. However, the corrosion current density decreases by about three orders of magnitude (from $21.17 \mu \mathrm{A} \times \mathrm{cm}^{-2}$ for the untreated surface to $\leq 0.04 \mu \mathrm{A} \times \mathrm{cm}^{-2}$ for the superhydrophobic surface), demonstrating that the instantaneous corrosion rate of aluminum alloy decreases when the water repellency of the surfaces increases.

The order of corrosion resistance is A_FS, A_NS, A_WS, and A_R. This order is consistent with water repellency results, where sliding angles to the superhydrophobic surfaces were in the order of A_WS > A_NS > A_FS. In particular, the A_FS is the noblest specimen thanks to its high water repellency.

Thus, the elaborated superhydrophobic aluminum alloy surfaces have better corrosion resistance than the as-received AA6082-T6 alloys. In fact, the corrosion behavior of the samples is affected by the surface morphology. The superhydrophobic surface traps air within the valleys on the hierarchical interface when immersed in seawater $(3.5 \mathrm{wt} . \% \mathrm{NaCl})$ solution. Therefore, the trapped air in micro/nano-hierarchical structures of the superhydrophobic samples acts as an "air cushion" to prevent the penetration of corrosive ions $\left(\mathrm{Cl}^{-}\right)$, effectively resulting in excellent corrosion protection [48-50]. These results are in significant accordance with literature. In fact, Feng et al. [27] showed that the superhydrophobic aluminum alloy surfaces have better corrosion resistance than untreated aluminum alloys. In addition, He et al. [51] found that the superhydrophobic surfaces improved the corrosion resistance of aluminum in sterile seawater.

To sum up, the proposed sol-gel self-assembling approach of the silane layer coupled with the different roughening treatments significantly improved the water repellency and, thus, the corrosion resistance of the aluminum alloy AA6082-T6. In addition, this approach opens the door to various industrial applications thanks to the controllable wettability behavior.

These results are promising for further investigation to understand the effect of hierarchical morphologies on the interactions of the surface with liquids, at different polarities, not only in static but also in dynamic conditions.

\section{Conclusions}

Superhydrophobic surfaces were successfully obtained by the cooperation of a low-surface-energy self-assembled silane coating and surface roughness with a hierarchical micro/nano-structure. The wettability behavior of the aluminum alloy surface varies with the roughening processes. In fact, the highest contact angle $\approx 180^{\circ}$ and the lowest sliding angle were achieved by $\mathrm{HF} / \mathrm{HCl}$ chemical etching. However, a very high water adhesion $\left(\mathrm{SA}>90^{\circ}\right)$ coupled with high contact angle $\left(174^{\circ}\right)$ were obtained by the boiling process. An intermediate sliding angle with a quite low contact angle $\left(160^{\circ}\right)$, compared to the other samples, was observed on the surface prepared by $\mathrm{HNO}_{3} / \mathrm{HCl}$ chemical etching. This difference in contact and sliding angles is due to the different obtained morphologies, which affect the silane monolayer deposition on the surface of the aluminum alloy. The corrosion resistance of the superhydrophobic aluminum surfaces was evaluated by electrochemical tests in seawater. The corrosion resistance increases with the enhancement of surface water repellency, indicating that the surface with a lower sliding angle has better corrosion resistance. Thus, the superhydrophobic aluminum alloy surfaces demonstrate a significant increase in the corrosion resistance compared to the as-received one.

Author Contributions: Conceptualization, L.C. and E.P.; Methodology, L.C. Table. and E.P.; Software, A.K.; Validation, E.P.; Formal Analysis, A.K.; Investigation, L.C. and A.K.; Data Curation, A.K.; Writing-Original Draft Preparation, A.K.; Writing-Review and Editing, L.C. and E.P.; Supervision, E.P. All authors have read and agreed to the published version of the manuscript.

Funding: This research received no external funding.

Conflicts of Interest: The authors declare no conflict of interest. 


\section{References}

1. Simpson, J.T.; Hunter, S.R.; Aytug, T. Superhydrophobic materials and coatings: A review. Rep. Prog. Phys. 2015, 78, 086501. [CrossRef] [PubMed]

2. Zhou, C.; Chen, Z.; Yang, H.; Hou, K.; Zeng, X.; Zheng, Y.; Cheng, J. Nature-Inspired Strategy toward Superhydrophobic Fabrics for Versatile Oil/Water Separation. ACS Appl. Mater. Interfaces 2017, 9, 9184-9194. [CrossRef] [PubMed]

3. Vazirinasab, E.; Jafari, R.; Momen, G. Application of superhydrophobic coatings as a corrosion barrier: A review. Surf. Coat. Technol. 2018, 341, 40-56. [CrossRef]

4. Ran, M.; Zheng, W.; Wang, H. Fabrication of superhydrophobic surfaces for corrosion protection: A review. Mater. Sci. Tech. 2019, 35, 313-326. [CrossRef]

5. Zheng, S.; Li, C.; Fu, Q.; Hu, W.; Xiang, T.; Wang, Q.; Du, M.; Liu, X.; Chen, Z. Development of stable superhydrophobic coatings on aluminum surface for corrosion-resistant, self-cleaning, and anti-icing applications. Mater. Des. 2016, 93, 261-270. [CrossRef]

6. Zhang, B.; Wang, J.; Zhang, J. Bioinspired one step hydrothermal fabricated superhydrophobic aluminum alloy with favorable corrosion resistance. Colloids Surf. A Physicochem. Eng. Asp. 2020, 589, 124469. [CrossRef]

7. Ruan, M.; Li, W.; Wang, B.; Luo, Q.; Ma, F.; Yu, Z. Optimal conditions for the preparation of superhydrophobic surfaces on al substrates using a simple etching approach. Appl. Surf. Sci. 2012, 258, 7031-7035. [CrossRef]

8. Chen, Z.; Guo, Y.; Fang, S. A facial approach to fabricate superhydrophobic aluminum surface. Surf. Interface Anal. 2010, 42, 1-6. [CrossRef]

9. Shi, Y.; Xiao, X.; Zhang, W. Facile fabrication of superhydrophobic surface with needle-like microflower structure on aluminum substrate. J. Coat. Technol. Res. 2015, 12, 1143-1151. [CrossRef]

10. Dou, W.; Wu, J.; Gu, T.; Wang, P.; Zhang, D. Preparation of super-hydrophobic micro-needle CuO surface as a barrier against marine atmospheric corrosion. Corros. Sci. 2018, 131, 156-163. [CrossRef]

11. Li, X.; Zhang, Q.; Guo, Z.; Shi, T.; Yu, J.; Tang, M.; Huang, X. Fabrication of superhydrophobic surface with improved corrosion inhibition on 6061 aluminum alloy substrate. Appl. Surf. Sci. 2015, 342, 76-83. [CrossRef]

12. Feng, L.; Yan, Z.; Qiang, X.; Liu, Y.; Wang, Y. Facile formation of superhydrophobic aluminum alloy surface and corrosion-resistant behavior. Appl. Phys. A Mater. Sci. Process. 2016, 122, 122. [CrossRef]

13. Fadeev, A.Y.; McCarthy, T.J. Self-assembly is not the only reaction possible between alkyltrichlorosilanes and surfaces: Monomolecular and oligomeric covalently attached layers of dichloro- and trichloroalkylsilanes on silicon. Langmuir 2000, 16, 7268-7274. [CrossRef]

14. Saleema, N.; Sarkar, D.K.; Paynter, R.W.; Chen, X.-G. Superhydrophobic Aluminum Alloy Surfaces by a Novel One-Step Process. Appl. Mater. Interfaces 2010, 2, 2500-2502. [CrossRef]

15. Pantoja, M.; Abenojar, J.; Martinez, M.A. Influence of the type of solvent on the development of superhydrophobicity from silane-based solution containing nanoparticles. Appl. Surf. Sci. 2017, 397, 87-94. [CrossRef]

16. Khodaei, M.; Shadmani, S. Superhydrophobicity on aluminum through reactive-etching and TEOS/GPTMS/nano-Al2O3 silane-based nanocomposite coating. Surf. Coat. Technol. 2019, 374, 1078-1090. [CrossRef]

17. Calabrese, L.; Khaskhoussi, A.; Patanè, S.; Proverbio, E. Assessment of Super-Hydrophobic Textured Coatings on AA6082 Aluminum Alloy. Coatings 2019, 9, 352. [CrossRef]

18. Song, X.; Zhai, J.; Wang, Y.; Jiang, L. Fabrication of Superhydrophobic Surfaces by Self-Assembly and Their Water-Adhesion Properties. J. Phys. Chem. B 2005, 109, 4048-4052. [CrossRef]

19. Gittins, D.I.; Bethell, D.; Nichols, R.J.; Schiffrin, D.J. Diode-like electron transfer across nanostructured films containing a redox ligand. J. Mater. Chem. 2000, 10, 79-83. [CrossRef]

20. RIZZO, H.F.; BIDWELL, L.R. Formation and Structure of SiB4. J. Am. Ceram. Soc. 1960, 43, 550-552. [CrossRef]

21. McArthur, E.A.; Ye, T.; Cross, J.P.; Petoud, S.; Borguet, E. Fluorescence Detection of Surface-Bound Intermediates Produced from UV Photoreactivity of Alkylsiloxane SAMs. J. Am. Chem. Soc. 2004, 126, 2260-2261. [CrossRef] [PubMed]

22. Fadeev, A.Y.; Helmy, R.; Marcinko, S. Self-assembled monolayers of organosilicon hydrides supported on titanium, zirconium, and hafnium dioxides. Langmuir 2002, 18, 7521-7529. [CrossRef] 
23. Yin, L.; Wang, Y.; Ding, J.; Wang, Q.; Chen, Q. Water condensation on superhydrophobic aluminum surfaces with different low-surface-energy coatings. Appl. Surf. Sci. 2012, 258, 4063-4068. [CrossRef]

24. Feng, L.; Che, Y.; Liu, Y.; Qiang, X.; Wang, Y. Fabrication of superhydrophobic aluminium alloy surface with excellent corrosion resistance by a facile and environment-friendly method. Appl. Surf. Sci. 2013, 283, 367-374. [CrossRef]

25. Kumar, A.; Gogoi, B. Development of durable self-cleaning superhydrophobic coatings for aluminium surfaces via chemical etching method. Tribol. Int. 2018, 122, 114-118. [CrossRef]

26. Zhang, B.; Zeng, Y.; Wang, J.; Sun, Y.; Zhang, J.; Li, Y. Superamphiphobic aluminum alloy with low sliding angles and acid-alkali liquids repellency. Mater. Des. 2020, 188, 108479. [CrossRef]

27. Feng, L.; Zhang, H.; Wang, Z.; Liu, Y. Superhydrophobic aluminum alloy surface: Fabrication, structure, and corrosion resistance. Colloids Surf. A Physicochem. Eng. Asp. 2014, 441, 319-325. [CrossRef]

28. Zhang, Y.; Wu, J.; Yu, X.; Wu, H. Low-cost one-step fabrication of superhydrophobic surface on Al alloy. Appl. Surf. Sci. 2011, 257, 7928-7931. [CrossRef]

29. Singh, D.D.N.; Chaudhary, R.S.; Agarwal, C.V. Corrosion Characteristics of Some Aluminum Alloys in Nitric Acid. J. Electrochem. Soc. 1982, 129, 1869-1874. [CrossRef]

30. Qian, B.; Shen, Z. Fabrication of superhydrophobic surfaces by dislocation-selective chemical etching on aluminum, copper, and zinc substrates. Langmuir 2005, 21, 9007-9009. [CrossRef]

31. Kim, J.H.; Mirzaei, A.; Kim, H.W.; Kim, S.S. Realization of superhydrophobic aluminum surfaces with novel micro-terrace nano-leaf hierarchical structure. Appl. Surf. Sci. 2018, 451, 207-217. [CrossRef]

32. Lee, Y.; Ju, K.Y.; Lee, J.K. Stable biomimetic superhydrophobic surfaces fabricated by polymer replication method from hierarchically structured surfaces of al templates. Langmuir 2010, 26, 14103-14110. [CrossRef] [PubMed]

33. Zhang, H.S.; Endrino, J.L.; Anders, A. Comparative surface and nano-tribological characteristics of nanocomposite diamond-like carbon thin films doped by silver. Appl. Surf. Sci. 2008, 255, 2551-2556. [CrossRef]

34. Horváth, R.; Czifra, Á.; Drégelyi-Kiss, Á. Effect of conventional and non-conventional tool geometries to skewness and kurtosis of surface roughness in case of fine turning of aluminium alloys with diamond tools. Int. J. Adv. Manuf. Technol. 2015, 78, 297-304. [CrossRef]

35. Kim, D.; Sasidharanpillai, A.; Yun, K.H.; Lee, Y.; Yun, D.J.; Park, W.I.; Bang, J.; Lee, S. Assembly mechanism and the morphological analysis of the robust superhydrophobic surface. Coatings 2019, 9, 472. [CrossRef]

36. Sun, W.; Wang, L.; Yang, Z.; Li, S.; Wu, T.; Liu, G. Fabrication of polydimethylsiloxane-derived superhydrophobic surface on aluminium via chemical vapour deposition technique for corrosion protection. Corros. Sci. 2017, 128, 176-185. [CrossRef]

37. Kulkarni, S.A.; Ogale, S.B.; Vijayamohanan, K.P. Tuning the hydrophobic properties of silica particles by surface silanization using mixed self-assembled monolayers. J. Colloid Interface Sci. 2008, 318, 372-379. [CrossRef]

38. Larkin, P. Infrared and Raman Spectroscopy: Principles and Spectral Interpretation; Elsevier: Oxford, UK, 2011.

39. Wenzel, R.N. Surface roughness and contact angle. J. Phys. Colloid Chem. 1949, 53, 1466-1467. [CrossRef]

40. Cassie, A.B.D.; Baxter, S. Wettability of porous surfaces. Trans. Faraday Soc. 1944, 40, 546-551. [CrossRef]

41. Zhang, H.; Yin, L.; Shi, S.; Liu, X.; Wang, Y.; Wang, F. Facile and fast fabrication method for mechanically robust superhydrophobic surface on aluminum foil. Microelectron. Eng. 2015, 141, 238-242. [CrossRef]

42. Nie, H.Y. Self-assembled monolayers of octadecylphosphonic acid and polymer films: Surface chemistry and chemical structures studied by time-of-flight secondary ion mass spectrometry. Surf. Interface Anal. 2017, 49, 1431-1441. [CrossRef]

43. Nie, H.Y.; Walzak, M.J.; McIntyre, N.S. Delivering octadecylphosphonic acid self-assembled monolayers on a Si wafer and other oxide surfaces. J. Phys. Chem. B 2006, 110, 21101-21108. [CrossRef] [PubMed]

44. Calabrese, L.; Bonaccorsi, L.; Caprì, A.; Proverbio, E. Electrochemical behavior of hydrophobic silane-zeolite coatings for corrosion protection of aluminum substrate. J. Coat. Technol. Res. 2014, 11, 883-898. [CrossRef]

45. Calabrese, L.; Bonaccorsi, L.; Proverbio, E. Corrosion protection of aluminum 6061 in NaCl solution by silane-zeolite composite coatings. J. Coat. Technol. Res. 2012, 9, 597-607. [CrossRef]

46. Correa-Borroel, A.L.; Gutierrez, S.; Arce, E.; Cabrera-Sierra, R.; Herrasti, P. Organosilanes and polypyrrole as anticorrosive treatment of aluminium 2024. J. Appl. Electrochem. 2009, 39, 2385-2395. [CrossRef] 
47. Olawuni, E.O.; Drowoju, M.O.; Asafa, T.B.; Mudashiru, L.O. Development of Piston Materials from Discarded Aluminum Piston Alloyed with Zirconium Diboride and Snailshells. Int. J. Adv. Sci. Eng. 2018, 5, 818. [CrossRef]

48. Liu, T.; Chen, S.; Cheng, S.; Tian, J.; Chang, X.; Yin, Y. Corrosion behavior of super-hydrophobic surface on copper in seawater. Electrochim. Acta 2007, 52, 8003-8007. [CrossRef]

49. Mohamed, A.M.A.; Abdullah, A.M.; Younan, N.A. Corrosion behavior of superhydrophobic surfaces: A review. Arab. J. Chem. 2015, 8, 749-765. [CrossRef]

50. Liu, C.; Su, F.; Liang, J. Facile fabrication of a robust and corrosion resistant superhydrophobic aluminum alloy surface by a novel method. RSC Adv. 2014, 4, 55556-55564. [CrossRef]

51. He, T.; Wang, Y.; Zhang, Y.; Lv, Q.; Xu, T.; Liu, T. Super-hydrophobic surface treatment as corrosion protection for aluminum in seawater. Corros. Sci. 2009, 51, 1757-1761. [CrossRef]

(C) 2020 by the authors. Licensee MDPI, Basel, Switzerland. This article is an open access article distributed under the terms and conditions of the Creative Commons Attribution (CC BY) license (http://creativecommons.org/licenses/by/4.0/). 